\title{
Elevated Intrabolus Pressure Predicts Abnormal Timed Barium Esophagram in Esophagogastric Junction Outflow Obstruction
}

\author{
Matthew Hoscheit ${ }^{1 *}$ and Scott Gabbard ${ }^{2}$ \\ Departments of ${ }^{1}$ Internal Medicine and ${ }^{2}$ Gastroenterology, Cleveland Clinic Foundation, Cleveland, OH, USA
}

\begin{abstract}
Background/Aims
Timed barium esophagram (TBE) is used the classification of esophageal motility disorders and assessing esophageal function. Currently, there are no published studies examining the relationship between high-resolution manometry and TBE in patients with esophagogastric junction outflow obstruction (EGJOO). This study seeks to evaluate this relationship and identify manometric variables that may indicate further evaluation using TBE.
\end{abstract}

\section{Methods}

Retrospective review of medical records identified patients with a diagnosis of EGJOO per the Chicago classification version 3.0. TBE was performed using standard protocol. Patients were divided into 2 groups based on complete emptying or persistence of standing barium column at 5 minutes.

\section{Results}

Eleven patients were identified with EGJOO who underwent both high-resolution manometry and TBE within 3 months. Five patients had no standing barium column at 5 minutes, while 6 patients had a persistent barium column. Mean age of each group was 54.0 years and 57.8 years, respectively. Patients with abnormal TBE were found to have significantly elevated intrabolus pressure (IBP) compared with patients who had a normal TBE.

\section{Conclusions}

In our study, we found significant differences in IBP between these patient groups. These findings suggest that patients with EGJOO and elevated IBP may prompt further clinical evaluation with TBE in order to clarify clinical diagnosis and guide therapeutic intervention.

(J Neurogastroenterol Motil 2019;25:521-524)

\section{Key Words}

Chicago; Esophageal motility disorders; Gastrointestinal transit; Humans; Manometry

Received: February 12, 2019 Revised: None Accepted: July 20, 2019

(a) This is an Open Access article distributed under the terms of the Creative Commons Attribution Non-Commercial License (http://creativecommons. org/licenses/by-nc/4.0) which permits unrestricted non-commercial use, distribution, and reproduction in any medium, provided the original work is properly cited.

*Correspondence: Matthew Hoscheit, MD

Department of Internal Medicine, Cleveland Clinic Foundation, 9500 Euclid Avenue, Cleveland, OH 44195, USA

Tel: +1-216-219-9185, E-mail: matthew.j.hoscheit@gmail.com 


\section{Introduction}

Esophagogastric junction outflow obstruction (EGJOO) has increasingly become recognized as a distinct entity within the class of esophageal motility disorders (EMD). Per the Chicago classification version 3.0 (v3.0), EGJOO is "elevated median integrated relaxation pressure (IRP) with intact or weak peristalsis such that the criteria for achalasia are not fulfilled." ${ }^{1}$ The utilization of highresolution manometry (HRM) has allowed for EGJOO to be distinguished as a variant of achalasia. As our understanding our EGJOO has improved, it has become understood to be a heterogenous clinical pathology, with both functional and anatomical etiologies. ${ }^{1-3}$ This has limited success in the treatment of EJGOO; there is no universal treatment for the condition. ${ }^{4}$ Timed barium esophagram (TBE) has long been utilized in the diagnosis of achalasia and has been used as a diagnostic tool in EGJOO. It is used to classify esophageal motility disorders and assess esophageal function before and after interventional therapy. ${ }^{5}$ To our knowledge, no studies have examined HMR findings to EGJOO that may predict abnormal esophageal emptying on TBE. We seek to evaluate the relationship between TBE and HRM in patients with EGJOO; specifically, if any manometric findings would be predictive of abnormal emptying on TBE.

\section{Materials and Methods}

A retrospective cohort study was performed by reviewing medical records of 9934 patients who underwent HRM from February 2013 to September 2015 at the Cleveland Clinic Foundation. The diagnosis of EGJOO was made per the Chicago classification v3.0 by a gastroenterologist experienced in interpreting HRM. Patients with mechanical obstruction or a known history or subsequent development of any subtype of achalasia were excluded. Those without a TBE performed within 3 months of HRM were also excluded.

\section{High-resolution Manometry}

A 36-channel, solid-state, catheter system was used to perform the HRM (Medtronic, Minneapolis, MN, USA). In the upright position, our patients performed 10 swallows of $5 \mathrm{~mL}$ of water. ManoView software (Medtronic) was used to analyze the data. Manometric variables included lower esophageal sphincter basal pressure, integrated relaxation pressure, intrabolus pressure (IBP), distal latency, and distal contractile integral (DCI). These variables, per the Chicago classification v3.0, were used to determine EGJOO in each patient (Fig. 1). ${ }^{6}$ A gastroenterologist trained in HRM reviewed all of the tracings.

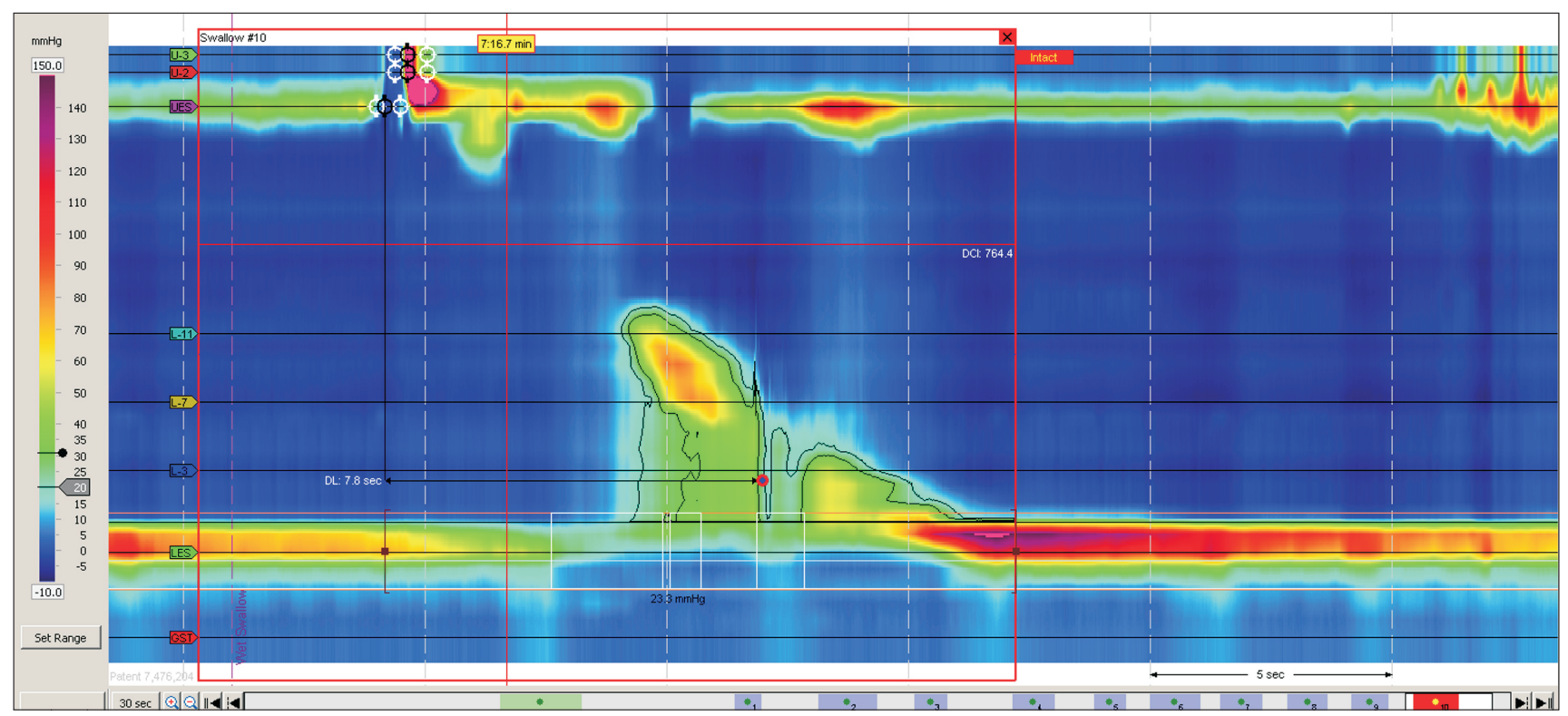

Figure 1. High-resolution manometry in an esophagogastric junction outflow obstruction (EJGOO) subject. Pressure topography showing normal esophageal peristalsis and impaired lower esophageal sphincter relaxation, consistent with EGJOO. 


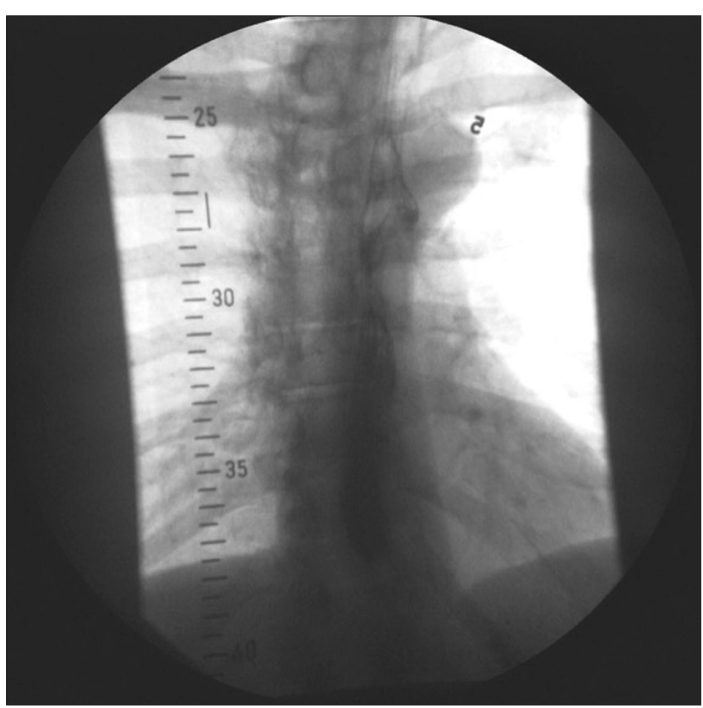

Figure 2. Timed barium esophagram (TBE) in an esophagogastric junction outflow obstruction (EJGOO) subject showing barium retention at 5 minutes.

\section{Timed Barium Esophagram}

TBE was performed using standard protocol for achalasia, which has been previously described. ${ }^{7}$ Patients were instructed to drink 8 oz of low density barium in the standing position with films obtained at 1 minute and 5 minutes to assess barium emptying. Patients were divided into 2 groups based on complete emptying or persistence of standing barium column at 5 minutes. A normal TBE was established if the standing barium column height was < $5 \mathrm{~cm}$ following 5 minutes, while an abnormal TBE was established if the standing barium column height was $<5 \mathrm{~cm}$ following $5 \mathrm{~min}$ utes (Fig. 2) ${ }^{8,9}$ Radiologists trained in body imaging interpreted all of the TBE. Examined variables included barium height at $1 \mathrm{~min}-$ ute and 5 minutes (in $\mathrm{cm}$ ), barium width at 1 minute and 5 minutes (in $\mathrm{cm}$ ).

\section{Results}

Eleven patients were identified with EGJOO who underwent both HRM and TBE within a 3-month period at our institution. 5 patients had no standing barium column at 5 minutes, while 6 patients had a persistent barium column at 5 minutes. The mean age of each group was 54 years and 57.8 years, respectively. Differences in IRP, IBP, and DCI between patients with normal and abnormal TBE results are provided (Table). Patients with abnormal TBE had no differences in IRP or DCI on HRM compared to patients
Table. Comparison of High-resolution Manometry Parameters Between Patients With Normal and Abnormal Timed Barium Esophagram

\begin{tabular}{lccc}
\hline & $\begin{array}{c}\text { Barium } \\
\text { emptying } \\
\text { at } 5 \text { min }\end{array}$ & $\begin{array}{c}\text { Standing bar- } \\
\text { ium column } \\
\text { at 5 min }\end{array}$ & P-value \\
\hline No. of patients & 5 & 6 & \\
Mean age (yr) & 54.0 & 57.8 & \\
Mean IRP (mmHg) & 20.34 & 24.18 & 0.307 \\
Mean IBP (mmHg) & 19.42 & 33.06 & 0.021 \\
Mean DCI (mmHg) & 5693.36 & 2146.90 & 0.194 \\
\hline
\end{tabular}

IRP, integrated relaxation pressure; IBP, intrabolus pressure; DCI, distal contractile integral.

with normal TBE. Significantly elevated IBP was found in patients with abnormal TBE in comparison to those with a normal TBE. All patients with delayed emptying at 5 minutes had an IBP greater than $24 \mathrm{mmHg}$; all but 1 patient with normal emptying had an IBP less than $24 \mathrm{mmHg}$.

\section{Conclusion}

Though HRM is important in the recognition of EGJOO, the role of TBE in this disease remains unclear. Our analysis of patients diagnosed with EGJOO and having TBE and HRM within 3 months has shown that an abnormally elevated intrabolus pressure on HRM may be predictive of abnormal barium emptying seen in TBE. Furthermore, we believe that an IBP greater than $24 \mathrm{mmHg}$ may be predictive of abnormal emptying in TBE. IRP and DCI were not associated with delayed emptying in patients with EGJOO.

The clinical significance of EGJOO remains to be defined. ${ }^{10,1}$ To clarify our understanding of this disease, the value diagnostic testing outside of HRM ought to be explored. The data surrounding the benefit of TBE in EGJOO is scarce, and future studies are needed to elucidate the role of TBE in guiding the management of EGJOO. Our evidence suggests that patients with EGJOO and IBP $>24 \mathrm{mmHg}$ may prompt further clinical evaluation with TBE to clarify the clinical diagnosis and guide therapeutic intervention.

Financial support: None.

Conflicts of interest: None. 
Author contributions: Matthew Hoscheit: planning/conducting study, interpreting data, and drafting/finalizing the manuscript; and Scott Gabbard: planning/conducting study, interpreting data, and editing the manuscript.

\section{References}

1. Kahrilas PJ, Bredenoord AJ, Fox M, et al. The Chicago classification criteria of esophageal motility disorders, v3.0. Neurogastroenterol Motil 2015;27:160-174.

2. Shupack D, Katzka D, Geno DM, Ravi K. The clinical significance of esophagogastric junction outflow obstruction and hypercontractile esophagus in high resolution esophageal manometry. Neurogastroenterol Motil 2017;29:1-9.

3. Blonski W, Kumar A, Feldman J, Richter JE. Timed barium swallow: diagnostic role and predictive value in untreated achalasia, esophagogastric junction outflow obstruction, and non-achalasia dysphagia. Am J Gastroenterol 2018;113:196-203.

4. Ihara E, Muta K, Fukaura K, Nakamura K. Diagnosis and treatment strategy of achalasia subtypes and esophagogastric junction outflow obstruction based on high-resolution manometry. Digestion 2017;95:29-35.

5. Clayton SB, Patel R, Richter JE. Functional and anatomic esophago- gastric junction outflow obstruction: manometry, timed barium esophagram findings, and treatment outcomes. Clin Gastroenterol Hepatol 2016;14:907-911.

6. Bredenoord AJ, Fox M, Kahrilas PJ, et al. Chicago classification criteria of esophageal motility disorders defined in high resolution esophageal pressure topography. Neurogastroenterol Motil 2012;24:57-65.

7. de Oliveira JM, Birgisson S, Doinoff C, et al. Timed barium swallow: a simple technique for evaluating esophageal emptying in patients with achalasia. AJR Am J Roentgenol 1997;169:473479.

8. Nicodème F, de Ruigh A, Xiao Y, et al. A comparison of symptom severity and bolus retention with Chicago classification esophageal pressure topography metrics in patients with achalasia. Clin Gastroenterol Hepatol 2013;11:131-137.

9. Rohof WO, Lei A, Boeckxstaens GE. Esophageal stasis on a timed barium esophagogram predicts recurrent symptoms in patients with longstanding achalasia. Am J Gastroenterol 2013;108:49-55.

10. van Hoeij FB, Smout AJ, Bredenoord AJ. Characterization of idiopathic esophagogastric junction outflow obstruction. Neurogastroenterol Motil 2015;27:1310-1316

11. Pérez-Fernández MT, Santander C, Marinero A, Burgos-Santamaría D, Chavarría-Herbozo C. Characterization and follow-up of esophagogastric junction outflow obstruction detected by high resolution manometry. Neurogastroenterol Motil 2016;28:116-126. 